\title{
Validating a theoretical model for hotel brand love amongst young Indian tourists
}

\author{
Abhigyan Sarkar * \\ Ghaziabad-Department of Marketing, Institute of Management Technology, Ghaziabad, India
}

\author{
Keywords \\ Hotel brand love \\ Hotel location emotion \\ Tourists' emotional labour \\ Received: 16 March 2019 \\ Accepted: 17 June 2019 \\ Published: 26 August 2019
}

\begin{abstract}
This empirical article investigates various factors that would create hotel brand love in tourist's minds and potential outcomes of such hotel brand love in the emerging Indian hotel sector. Based on reviewing relevant extant research, a set of hypotheses are formulated. Data are collected by surveying young Indian travelers and analyzed using confirmatory factor analysis and structural equation modeling. The study findings support that other customer perception, hotel service quality, hotel brand foreignness, and hotel location emotion significantly predict hotel brand love among young Indian tourists. Hotel brand love, in turn, predicts conative hotel brand loyalty and tourist's emotional labor. This study contributes to the existing body of hotel service theory by validating some important causal relationships between various tourist psychological factors associated with hotel brand love in a comprehensive theoretical framework for the first time in the context of young Indian tourists. The model validated is expected to guide the emerging market hotel managers to elicit hotel brand love among young adult tourists.
\end{abstract}

(C) 2019 The Author(s). Published by TAF Publishing.

\section{INTRODUCTION}

Destination travel service providers across the globe are vying to enrich tourists' experiences by providing them with a meaningful travel experience (Gretzel, Fesenmaier, Formica, \& O'Leary, 2006). The tourist experience is a result of various factors which act simultaneously like hotels that the tourists stay in, and attractions of the tourist spots which combine to generate an overall tourist experience (Murphy, Pritchard, \& Smith, 2000). A significant factor that shapes tourists' travel experience is the service provided by the hotel that tourists stay in (Blain, Levy, \& Ritchie, 2005; Murphy et al., 2000; Yaemjamuang, 2017). The prime importance of hotel factor lies in its ability to influence tourists' repeat visit intention. Tourists wish to experience positive emotions like comfort and pleasure while planning a journey (Kwortnik Jr \& Ross Jr, 2007). These expected positive emotions can be confirmed or disconfirmed (Oliver, 1980) based on their encounters with the hotels that they stay in, and services provided by the hotels.

Todays' hotels are finding it increasingly difficult to retain a loyal customer base due to globalization and tough mar- ket competition (Kandampully \& Suhartanto, 2000; Mason, Tideswell, \& Roberts, 2006; Qiu, Ye, Bai, \& Wang, 2015; Xie \& Chen, 2014). In this context, it is managerially challenging to elicit long-term positive emotions like brand love (Carroll \& Ahuvia, 2006) among hotel customers. Brand love is an important predictor of desirable marketing outcomes like conative and behavioural brand loyalty (Batra, Ahuvia, \& Bagozzi, 2012; Carroll \& Ahuvia, 2006). Significant prior research studied how consumers can form attitudinal loyalty towards brands through loving the brands in fast moving consumer packaged goods sector, and brand love is regarded as one of the core marketing concepts going beyond the traditional satisfaction research (Carroll \& Ahuvia, 2006; Kuo \& Chen, 2015). However, research investigating brand love in a hotel service context is scarce. Mattila (2006) suggests that "a more detailed analysis of brandlevel effects might be a fruitful avenue for gaining further insight into guest loyalty" in today's highly commoditized hotel industry. This research intends to fill this knowledge gap by identifying a set of antecedents and consequences of hotel brand love based on prior literature review, and empiri-

\footnotetext{
${ }^{*}$ corresponding author: Abhigyan Sarkar

†email: juhi.gahlot.sarkar@gmail.com
} 
cally testing the inter-relationships between the concepts. The remaining paper is organized as follows. First, the possible antecedents and consequences of hotel brand love have been identified, and their inter-relationships have been hypothesized based on prior literature review. Second, the hypothesized relationships have been quantitatively tested among Indian luxury hotel consumers. Finally, the theoretical contributions and managerial implications of the study findings have been discussed along with future research directions.

\section{LITERATURE REVIEW}

What is Brand Love? Why is it Important in the Context of Hotel Brands?

Brand love is an affective consumer-brand relationship construct (Bergkvist \& Bech-Larsen, 2010) which includes brand emotion and passion (Carroll \& Ahuvia, 2006). Brand love does not represent mere emotional state of mind towards brand at a certain point of time; rather it is a relationship concept evolved over time (Batra et al., 2012). It is important for the brand marketers to formulate appropriate brand strategies to maintain a sustainable consumerbrand love relationship, as real brand lovers tend to show long-term conative brand loyalty, and spread positive brand word-of-mouth (Batra et al., 2012; Bergkvist \& BechLarsen, 2010; Carroll \& Ahuvia, 2006; Saputra \& Dewi, 2016). Brand love is structurally analogous to interpersonal love where brand is perceived as human (Batra et al., 2012; Bergkvist \& Bech-Larsen, 2010; Carroll \& Ahuvia, 2006; A. Sarkar, Ponnam, \& Murthy, 2012). However, the true nature of brand love at any state would be context specific (Batra et al., 2012). This implies that the nature of brand love, as well as its antecedents and consequences are likely to differ across industries. Brand love is scarcely researched in the context of hotel industry. Mattila (2006) states, "Customer loyalty is the key to success in today's commoditized hotel industry. To that end, many hotel companies offer frequent-guest programs. The reward programs are not enough to induce loyalty, however, in the absence of an emotional bond with the brand". Investigating hotel brand love would provide deeper insights into eliciting emotional bonding between tourist and hotel brands.

\section{Cognitive Satisfaction Predicting Affective Brand Love Via Affective Satisfaction}

Mann (1999) argues, "cognitive activity causally precedes an emotion in the flow of psychological events". Oliver (1999) also supports that cognition predicts affect. In theCarroll and Ahuvia (2006) propose that a percentage of satisfied customers would love a brand. In other words, satisfaction with the brand predicts brand love. Overall satisfaction contains both cognitive Oliver (1980) and affective (Ladhari, 2009; Stiles, Putnam, Wolf, \& James, 1979) elements. Hence, following Oliver (1999) it is posited that cognitive satisfaction predicts affective satisfaction, and affective satisfaction predicts more affective brand love. Thus, cognitive satisfaction, affective satisfaction and brand love are related, but distinct concepts, and it is important to understand how various hotel brand- related cues can generate them in a hotel service context.

Other Customer Perception (OCP): An Important Predictor of Customer Satisfaction in an Interactive Service Context Like Hotel

Grove and Fisk (1997) note that within a service environment when other customers present violate any informal code of conduct, it generates lower customer satisfaction. This notion of code of conduct is grounded in the role theory and behaviour setting theory. Building on these notions, prior research supports that several aspects of other customers simultaneously present in any interactive service environment would influence the focal customer's satisfaction (Bitner, 1990). In the same line, Brocato, Voorhees, and Baker (2012) state that the cues received from other customers simultaneously present in a service context in terms of perceived similarity of other customers with respect to self, individual's liking towards the physical appearances of other customers, and perceived appropriateness of the behaviours demonstrated by other customers together form OCP of the focal individual, and this OCP predicts focal customer's cognitive satisfactory approach intention towards the service firm (i.e., hotel).

\section{Perceived Hotel Service Quality (HSQ) Determining Customer Satisfaction}

The study conducted by Ladhari (2009) supports that perceived overall HSQ positively impacts emotional/affective hotel satisfaction. However, Ladhari (2009) ignored the role played by cognitive satisfaction in mediating the impact of HSQ on affective satisfaction, as it is already discussed that i) cognitive and affective satisfaction is distinct concepts; and ii) their measurement scales are also different. Brakus, Schmitt, and Zarantonello (2009) propose the scale to measure cognitive satisfaction which is modeled over Oliver (1980), and Ladhari (2009) used the scale to measure affective satisfaction only. Ladhari (2009) study also does not include OCP along with HSQ for obvious reason that OCP scale (Brocato et al., 2012) was published after Ladhari 
(2009) had published the study. Brocato et al. (2012) state, "Perceptions of other customers play an equivocal role to service quality in shaping the intentions of customers. Using the OCP scale along with traditional service quality measures (e.g., SERVQUAL), managers can gain deeper insight into the customer-related social influences that impact customers". The current study intends to investigate this aspect.

Hence, it is finally argued that both OCP and HSQ can explain the variance in cognitive hotel satisfaction better than HSQ alone, and cognitive satisfaction (Brakus et al., 2009; Oliver, 1980) in turn would predict affective hotel satisfaction (Ladhari, 2009) following the proposition of Oliver (1999). It is also posited that affective hotel satisfaction would predict more affective hotel brand love following the stage-wise (lower to higher-order attitudinal progression) attitude formation theory described by Oliver (1999). Brand love is a higher-order affective construct than satisfaction, and they are conceptually distinct (Carroll \& Ahuvia, 2006). Quantitative research is scarce examining the interrelationships between different satisfaction types (cognitive and affective) and brand love.

\section{Internationalization of Emerging Market Hotels and Perceived Hotel Brand Self-Expressiveness}

With the rapid increase in the scale of international travel by tourists, hotels are also getting internationalized across countries in terms of offering up market and business travel oriented facilities (Litteljohn, 1997). The same article shows that holdings of several famous hotel groups in hotels located outside their home countries largely increased from 1978 to 1997. Emerging Asian market hotels have also not been the exceptions. Prior research describes how during 1980 to 2012, Chinese hotels started entering into management contracts and joint ventures with overseas investors (Gu, Ryan, \& Yu, 2012). Thus, China's own hotels were divided into two groups through this internationalization process: i) hotels merged with the well-recognized foreign brands, and ii) the pure Chinese hotels that did not merge. The international hotels "appealed to a brand conscious domestic Chinese market" (Gu et al., 2012). This shows that perceived foreignness of hotel brand has a positive appeal towards brand-conscious emerging market tourists.

Foreign investment is also taking place in the Indian hotel sector in terms of joint ventures, mergers and acquisitions at a rapid pace (https://bit.ly/2qMQMi1). This makes Indian hotels ideal for investigation tourists' brand love. Foreign multi-national hotel companies are investing in Asian hotel sector increasingly including Indian hotels (S. Lee,
2008). Prior research in the context of emerging Asian market shows that Perceived Brand Foreignness (PBF) positively influences social status signalling value of brand in the eyes of emerging market consumers (Zhou, Yang, \& Hui, 2010). PBF represents the degree to which a brand represents foreign culture association in contrast to domestic culture association, i.e., individual's perception of the degree to which a hotel has adopted foreign management style or whether a large number of foreign customers come to the hotel. PBF does not necessarily mean foreign group ownership as defined by Zhou et al. (2010). In that respect, a hotel brand owned by any domestic business group can also score high on PBF due to other foreign culture association. Social signaling brand value as described by Zhou et al. (2010) is conceptually analogous to perceived social-self expressive ability of brand defined by Carroll and Ahuvia (2006). According to Carroll and Ahuvia (2006), brand social-self expressiveness enhances the perceived social image of consumer which in turn positively influences emotional brand love. Applying this notion to Indian hotel sector, it can be argued that perceived foreignness of hotel brand would enhance perceived social-self expressiveness of hotel brand which would in turn positively influence tourist's hotel brand love.

\section{Hotel Location Emotion}

Hotel location is an important factor with regard to success and profitability of a hotel (Yang, Wong, \& Wang, 2012). Hotel location is significantly associated with larger accommodation demand (Lockyer, 2005). Choosing an attractive destination or location for establishing hotel can provide significant competitive advantage to a hotel (Dwyer, Mellor, Livaic, Edwards, \& Kim, 2004). According to the discrete choice model of hotel location, return on investment or perceived utility of a hotel can be specified as a function of hotel's site attributes, i.e., surrounding environment of the hotel (Yang et al., 2012). Bergkvist and Bech-Larsen (2010) posit that tourist can emotionally love a destination or location. Hence, based on the prior research it can be deduced that tourist's positive emotion towards the location of a hotel is expected to be a predictor of loving the hotel. In other words, one's love towards the location of a hotel would be channelized towards loving the hotel, as the hotel becomes an integral part of its location.

\section{Conative Hotel Brand Loyalty}

Hotels are facing increasing difficulty retaining loyal customers due to the lack of perceived differentiation in the experiences provided by the competing hotels (Kandampully 
\& Suhartanto, 2000), and also due to the lack of developing strong emotional connections to hotel among consumers (Mattila, 2006). Prior research states that hotel customers should perceive greater value in reward or loyalty programs run by a hotel (Xie \& Chen, 2014). However, Mattila (2006) state, "The reward programs are not enough to induce loyalty, however, in the absence of an emotional bond with the brand. Instead, affective commitment-that emotional bond-is needed to ensure repeat patronage". Oliver (1999) proposes that affect predicts conative and irrational intention to re-purchase a consumption object i.e., brand. Carroll and Ahuvia (2006) study shows that affective brand love predicts conative brand loyalty. Conative loyalty is highly desired by the marketers in any industry, as it predicts actual behavioural loyalty i.e., repeat hotel patronage (Oliver, 1999).

\section{Consumer's Emotional Labour as an Outcome of Brand Love}

Emotional labour is defined as an act or behaviour of displaying one's emotion in an interactive organizational setting irrespective of whether the act is discrepant with the actual emotion felt internally by individual (Glomb \& Tews, 2004). The nature of this emotional labour is determined by one's internal state of emotional dissonance created in relation to the organizational interaction. Such emotional dissonance is defined as "the state that exists when there is a discrepancy between the emotional demeanour that an individual displays because it is considered appropriate, and the emotions that are genuinely felt but that would be inappropriate to display" (Mann, 1999). The absence of any emotional dissonance would result in genuinely positive emotional labour, and the presence of emotional dissonance would lead to faking positive or suppressing negative emotions when individual would not want to express his/her genuinely felt negative emotions in an interactive setting to avoid violating the prevailing organizational display rules (Glomb \& Tews, 2004). A true brand lover tends to protect the loved brand against all kinds of odds, and forgive the brand for making mistakes unless the mistakes are very severe (Hemetsberger, Kittinger-Rosanelli, \& Friedmann, 2009). Brand love is a strong and positive emotional relationship with the brand (Batra et al., 2012; Carroll \& Ahuvia, 2006) which would be actively maintained by a devotional or true brand lover (Hemetsberger et al., 2009). Hence, it is expected that a true brand lover who is in a deep devotional love with a brand would largely intend to express genuine positive emotion while interacting with the brand in the presence of other customers OCP, i.e., telling genuinely felt positive words about the brand (Batra et al., 2012; Carroll \& Ahuvia, 2006). In certain occasions, if a true brand lover feels any disappointment while interacting with the focal brand also, he/she would largely try to hide the emotional dissonance by faking positive and/or suppressing negative (disappointment) emotions actually felt until the emotional dissonance generated is severely hurting, as a real brand lover would want to maintain the relationship with brand actively, and protect the brand against all odds (Hemetsberger et al., 2009). For e.g., in a hotel service encounter context, a customer maintaining a long-term loving relationship with a hotel might get disappointed due to sudden increase in the room rates or costs of food items served, but he/she might choose to pay the premium without expressing his/her true negative feelings towards the hotel staff, and write a good feedback while checking out, as he/she would not want to hurt the brand. Few research works have been conducted on hotel service providers' and hotel employees' emotional labours (Kim, 2008; Lam \& Chen, 2012; J. J. Lee \& Ok, 2012). However, research is scarce investigating factors eliciting hotel customer's emotional labour, given that customers can also express different types of emotional labours in an interactive service context like hotel.

\section{HYPOTHESES FORMULATION}

The inter-relationships between relevant constructs described above in relation to hotel brand love are hypothesized in this section.

OCP significantly determines customer satisfaction in an interactive service setting (Martin, 1996). Prior research maintains that "the effects of some aspects of other customers influence on increasing customer satisfaction" (Brocato et al., 2012) are significant. Experiences derived from various brand related cues would influence cognitive customer satisfaction (Brakus et al., 2009). The other customers simultaneously present while consuming a service in an interactive service environment (i.e., hotel) would generate several cues that would impact cognitive customer satisfaction, and the subsequent future approach intention towards the service brand (Brocato et al., 2012). It is already discussed that the first stage of satisfaction would be cognitive followed by affect (Oliver, 1999). In hotel service context, it would be termed as Cognitive Hotel Satisfaction (CHS). According to Brocato et al. (2012), OCP has 3 dimensions namely perceived similarity with other customers (OCP-S), perceived behaviours of other customers (OCPB) and perceived appearances of other customers (OCP-A). Therefore, we hypothesize: 
H1: OCP-S predicts CHS.

H1-1: OCP-B predicts CHS.

H1-2: OCP-A predicts CHS.

As already discussed, CHS would predict emotional/Affective Hotel Satisfaction (AHS) following Oliver (1999). Like OCP, HSQ described by N. Y. Wong and Ahuvia (1998) also refers to cognitive judgement of hotel service related cues like tangibles, employees' behaviours and parameters eliciting brand reliance. Hence, it is expected that HSQ dimensions would influence CHS first, and CHS would in turn predict AHS following Oliver (1999) theoretical proposition that rational cognition predicts affect. N. Y. Wong and Ahuvia (1998) conceptualize HSQ in terms of 3 dimensions: perception of hotel employees (HSQ-E), perception of hotel tangibles (HSQ-T), and perceived reliability of hotel service (HSQ-R). Therefore, we hypothesize:

H1-3: HSQ-E predicts CHS.

H1-4: HSQ-T predicts CHS.

H1-5: HSQ-R predicts CHS.

H1-6: CHS predicts AHS.

It is already discussed that affective hotel satisfaction would predict more affective Hotel Brand Love (HBL), as Oliver (1999) states that consumption attitude tends to progress from a lower to higher order. Therefore, we hypothesize:

H2: AHS predicts HBL.

Prior research in the context of the emerging market shows that perceived brand foreignness positively influences perceived social signaling brand value (Zhou et al., 2010). Due to the acculturation process in terms of developing more favourable attitude towards developed foreign country originated brands compared to the nationally originated brands taking place among the brand conscious emerging market consumers, emerging market consumers tend to perceive a greater affection towards brands associated with developed foreign cultures (J. G. Sarkar, Sarkar, \& Ponnam, 2015). Here, it is to be noted that perceived brand foreignness refers to the degree to which brand is perceived to represent a foreign like cultural aspects, and not necessarily foreign ownership. In the context of emerging market hotels, this can refer to perceived international standards of accommodation facilities offered by a hotel (Pine, 2002). The social signalling brand value (Zhou et al., 2010) is conceptually similar to social-self expressiveness of brand defined by Carroll and Ahuvia (2006). Based on Carroll and Ahuvia (2006), social-self expressiveness of a hotel brand is defined as the degree to which a tourist perceives that being associated with the hotel brand would enhance his/her social image in front of the significant others. Though
Zhou et al. (2010) posit that in the context of China, perceived brand foreignness positively influences social status signalling value of brand, the authors don't clearly specify whether this foreignness would be in terms of brand's perceived association with developed or developing foreign country. In the context of emerging Indian market, J. G. Sarkar et al. (2015) show that Indians tend to perceive brands as social-self expressive, if the brands are perceived to be associated with developed foreign countries, and not developing countries. For e.g., an Indian customer might feel that it would enhance his/her social-self when he/she would tell others about his/her staying in the Taj hotel which is a very reputed hotel brand in India in terms of having facilities like any developed foreign country hotel. Staying in luxury hotels is significantly perceived as status symbol by many (Catrett \& Lynn, 1999). Therefore, in the context of Indian emerging market hotel sector, it is hypothesized:

H3: Perceived Hotel Brand Foreignness (PHBF) in terms of brand's association with any developed foreign country culture positively influences perceived Social-Self Expressiveness (SSE) of hotel brand.

Carroll and Ahuvia (2006) show that perceived selfexpressive ability of brand which includes both inner and social-self expressive ability predicts consumer's emotional brand love. Inner-self expressiveness is not considered to be relevant in the present analysis, as inner-self expressiveness is not directly related to the projection of consumer's social status, and this study focuses on status signalling hotel consumption behaviour. Shachar, Erdem, Cutright, and Fitzsimons (2011) show that consumers tend to rely on those brands much that would express their self-worth to the environment. Brand social-self expressiveness (Carroll \& Ahuvia, 2006) is same as perceived social status signalling brand value (Zhou et al., 2010) which is a cognitive value judgment, and expected to predict CHS. For example, if a tourist perceives a hotel to be social self-expressive or status enhancing, he/she would be first cognitively satisfied with the hotel brand. This cognitive satisfaction would in turn predict affective satisfaction. Hence, it is hypothesized: H4: SSE of hotel brand positively influences CHS.

The notion provided by the above hypotheses that cues related to OCP, HSQ and SSE impact CHS is supported by the expectancy disconfirmation theory (Oliver, 1980) of consumer satisfaction formation. This theory states that consumer's cognitive satisfaction is formed over time through comparing relevant object attribute cues against a precomparison expectation level set which are also additive over time. Oliver (1980) theory is based on Helson (1948) 
adaptation-level theory.

Prior research also shows that the perception of the location of a hotel influences tourist's choice of hotel (Bull, 1994; Lewis, 1985; Yavas \& Babakus, 2005). Utilizing compositional self-explication model, prior research shows that location of hotel appears to be an important hotel attribute that would predict tourist's hotel choice decision (K. K. Wong \& Chi-Yung, 2002). Though few prior studies show that hotel location preference is related to hotel preference; yet, little "empirical research has examined this issue explicitly" ((Shoval, McKercher, Ng, \& Birenboim, 2011). Prior research also states that a tourist can be emotional towards a place and love a place (Batra et al., 2012). According to Batra et al. (2012), location emotion (HLE) would have 3 dimensions: joy (HLE-J), love (HLE-L) and positive surprise (HLE-PS). Hotel location emotion and brand love both are affective attitude constructs (Oliver, 1999). Based on the above review it is expected that tourist's emotional liking towards the location (place) of a hotel would predict his/her love towards the hotel. Therefore, we hypothesize:

H5: Favourable HLE-J predicts HBL.

H5-1: Favourable HLE-L predicts HBL.

H5-2: Favourable HLE-PS predicts HBL.

Prior research supports that affective brand love predicts conative brand loyalty (Bergkvist \& Bech-Larsen, 2010; Batra et al., 2012; Carroll \& Ahuvia, 2006). Hence, in hotel brand context, it is hypothesized:

H6: HBL predicts Conative Hotel Brand Loyalty (CBL). Emotional labour or the expression of one's emotion in an interactive service consumption context would be genuinely positive when an individual does not experience any emotional dissonance in his/her internal emotion regulatory mechanism (Glomb \& Tews, 2004). Brand love is a highly positive emotion felt towards a brand (Batra et al., 2012; Carroll \& Ahuvia, 2006). Prior research shows that a true brand lover tends to demonstrate genuinely positive acts like spreading positive words about the brand (Batra et al., 2012; Carroll \& Ahuvia, 2006), and defending the loved brand against all odds (Hemetsberger et al., 2009) which would be genuine in nature or actually free from any internal emotional dissonance. Hence, in hotel brand love context, it is hypothesized:

H7: HBL predicts Genuine Positive Emotional Labour (GPEL).

Prior research also shows that consumers who are highly emotional about brands tend to "defend them against all odds" (Hemetsberger et al., 2009). The same authors also maintain that consumers genuinely in love with certain brands would try to maintain their brand relationships actively, and tend to terminate their brand relationships only if there is any major dyadic relationship stress like a major breakdown of trust. Minor brand "failures are likely to be forgiven" (Hemetsberger et al., 2009) by a real brand lover. Hence, in the context of true hotel brand love, a real brand lover might also feel emotional dissonance (Glomb \& Tews, 2004) occasionally when the individual did not actually like any minor mistake done by the hotel. Still, he/she is likely to show positive emotional expression (faking) and/or suppress negative internal emotion elicited while interacting with the hotel brand especially in a public context OCP, as he/she would try to forgive the minor mistakes made by the deeply loved brand with an objective to maintain a sustainable love relationship. Thus, Faking Positive Emotional Labour (FPEL) and/or suppressing negative emotion or Suppressed Negative Emotional Labour (SNEL) would also be the outcomes of minor emotional dissonance experienced in relation to the brand. For e.g., an individual who has already developed strong emotional love towards a hotel based on significant past interactions, might not report any negative expression even after finding the taste of any food item not to be satisfactory in a certain occasion. It is also assumed that a true brand lover would largely feel genuinely positive brand emotion, and emotional dissonance can be felt very occasionally if the brand commits minor mistakes (Hemetsberger et al., 2009). The reason is that true brand love represents strongly positive emotional relationship (Batra et al., 2012). As a true brand lover might experience low emotional dissonance sometimes, the effect of brand love on suppressed negative or fake positive emotional labour is expected to be weaker compared to the effect of brand love on GPEL. Therefore, in hotel brand context, it is hypothesized:

H7-1: An individual emotionally loving a hotel brand occasionally tends to express FPEL.

H7-2: An individual emotionally loving a hotel brand occasionally tends to express SNEL.

The model (Figure 1) summarizes all the above hypotheses formulated. In the model, each arrow flows from antecedent to respective outcome as hypothesized. The abbreviations for construct names used in the model are already explained in the text. 


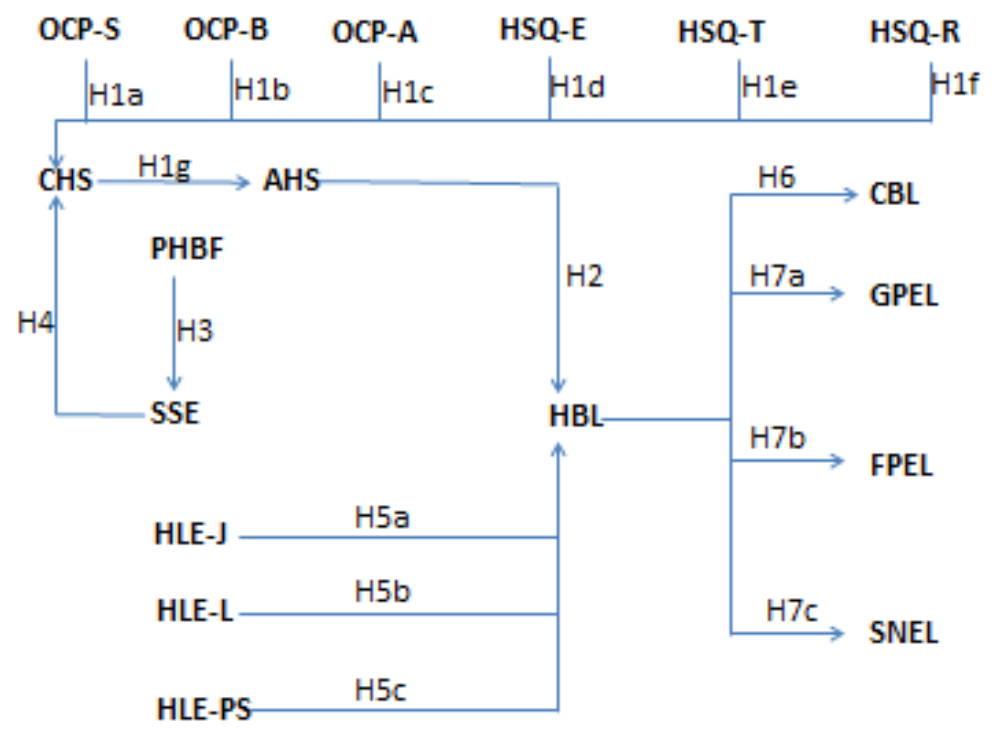

FIGURE 1. Conceptual framework for hotel brand love

\section{RESEARCH METHODOLOGY \\ Sampling and Data Collection}

The population of the study consisted of the young consumers of six five star rated luxury hotels located in Indian emerging market. Only the young adult respondents aged between 18 to 24 years were contacted. Young adult tourists were chosen as respondents, as prior research shows that a significant niche market of Asian Tourism consists of educated young people "who are keen to explore the world" (Chua \& Iwabuchi, 2008). As one study objective was to test relationship between perceived hotel brand foreignness and hotel brand love, only Indian customers were selected, and not foreign. A large sample was conveniently selected from this population. Luxury hotel was selected, as this category of hotel is likely to be perceived as socialself expressive due to having facilities of international standards (perceived brand foreignness). Out of these six hotels, three were foreign originated and three were national in terms of the country locations of the global headquarters of the hotels. The administrative managers of these hotels were contacted, and after taking the permission of hotel authorities, the questionnaires were administered to respondents when they were in their hotel rooms. First, each respondent was called over phone from hotel reception counter to know whether they would be willing to participate in this academic research related to hotel satisfaction against receiving a reward of 500 Indian rupees. Only those customers were called over phone who booked their hotel rooms at least 24 hours before as per hotel register the reason for which is explained below.

The questionnaire contained a screening statement: "This research on hotel satisfaction is being conducted solely for academic purposes. All responses provided by you would be kept confidential. Please spend some of your valuable time to fill the questionnaire, if i) you have booked your hotel room at least 24 hours or 1 day before from now; and ii) you have come for a leisure trip rather than business purpose". Business customers were excluded based on the assumption that they would have come for official works, rather than for love towards hotel or location. The screening criterion of ' 1 day before' was adopted at the discretion of the researchers to ensure a minimum level of prior interaction of respondent with the respective hotel brand, as the measurement of several study constructs (i.e., satisfaction and emotional labour) needed a certain minimum level of past interaction with brand, as per the adaptation level theory of satisfaction formation (Oliver, 1980).

The respondents were also instructed to fill the questionnaire keeping only the particular hotel brands and their locations in minds where they were staying while filling the questionnaires. In many cases, the researchers found a whole family present in a room including young adults (aged between 18 to 24 years), adults (aged above 24 years) and minor (aged below 18 years) family members. In such cases, the researchers administered questionnaires only to the young adult members. As hotel location emotion was an important variable, the research was conducted in the hotels located across popular coastal, hilly and metro city areas in order to ensure sufficient variation in the data. The data collection continued for about 7 months, and on an average, the researchers spent more than 30 days per hotel. This way the researchers approached total 1945 respondents across all six hotels over phones, and finally 1052 respondents properly filled questionnaires who satisfied the 
screening criterion. Out of these 1052 respondents, 642 were males. The age range of the respondents was 18 to 24 years with an average of 21.20 . The approximate range of gross annual family incomes as reported by the respondents were between 1487532 to 6389516 Indian rupees which would be considered as high-economic class in Indian context. This was expected, as the respondents were the customers of luxury hotels.

\section{Measures Used}

Items to measure all study constructs were adapted from scales already validated by prior research. Ten item Likert scale measuring HBL was adapted from Carroll and Ahuvia (2006). Thirteen items likert scale measuring OCP in terms of appearance (OCP-A), behaviour (OCP-B) and similarity (OCP-S) dimensions was adapted from Brocato et al. (2012). Five items-Likert scale measuring CHS was adapted from Brakus et al. (2009). The satisfaction scale used by Brakus et al. (2009) actually measures cognitive satisfaction, as the scale was "modeled after" (Brakus et al., 2009). Oliver (1980) cognitive satisfaction concept. Fifteen items likert scale measuring HLE in terms of three dimensions namely joy (HLE-J), love (HLE-L) and positive surprise (HLE-PS) were adapted from three dimensional destination emotion scale developed by Batra et al. (2012). Four items likert scale measuring SSE of hotel brand, and four items likert scale measuring CBL were adapted from Carroll and Ahuvia (2006). Total nineteen items likert scales measuring GPEL, FPEL and SNEL were adapted from Glomb and Tews (2004). Each likert item of the above mentioned scales was on a 1 to 7 point (1: Strongly disagree to 7: Strongly agree). Fifteen items likert scales measuring HSQ in terms of HSQ-E, HSQ-S and HSQ-T were adapted from N. Y. Wong and Ahuvia (1998). The HSQ items were also measured on a sevenpoint scale (1: Completely failed to meet my expectation to 7: Far exceeded my expectation). Four items semantic differential scale measuring PHBF in terms of developed foreign country association of focal brand were adapted from Zhou et al. (2010). Three items semantic differential scale measuring AHS was adapted from Ladhari (2009). Each semantic differential scale item was also based on 7 points such that two extreme points of each item represented bipolar adjectives, and the intermediate points were numbered from 2 to 6 . All scale items are shown in Table 1.

TABLE 1. Construct scale items and Composite Reliabiity (CR) values

\begin{tabular}{|c|c|c|}
\hline Factors & Items & CR \\
\hline \multirow[t]{11}{*}{ Hotel brand love } & & 0.86 \\
\hline & This is a wonderful hotel brand & \\
\hline & This hotel brand makes me feel good & \\
\hline & This hotel brand is totally awesome & \\
\hline & I have neutral feelings about this hotel brand* & \\
\hline & This hotel brand makes me very happy & \\
\hline & I love this hotel brand & \\
\hline & I have no particular feelings about this hotel brand* & \\
\hline & This hotel brand is a pure delight & \\
\hline & I am passionate about this hotel brand & \\
\hline & I am very attached to this hotel brand & \\
\hline \multirow[t]{5}{*}{ OCP-appearance } & & 0.88 \\
\hline & I like the appearances of other patrons who come to this hotel & \\
\hline & The other patrons in this hotel dress appropriately & \\
\hline & The other patrons in this hotel look nice & \\
\hline & The other patrons in this hotel look like they are my type of people & \\
\hline \multirow[t]{5}{*}{ OCP-behaviour } & & 0.8 \\
\hline & The behaviours of the other customers are appropriate in this hotel & \\
\hline & The other patrons seem to be friendly towards me in this hotel & \\
\hline & The other patrons behave well in this hotel & \\
\hline & The other patrons' behaviour in this hotel is pleasant & \\
\hline \multirow[t]{6}{*}{ OCP-Similarity } & & 0.82 \\
\hline & I can identify myself with other customers of this hotel & \\
\hline & I am similar to other customers of this hotel & \\
\hline & The other customers of this hotel are like me & \\
\hline & The other customers of this hotel are from backgrounds similar to myself & \\
\hline & I fit right in with the other customers of this hotel & \\
\hline
\end{tabular}


Table 1. Continue...

\begin{tabular}{ll}
\hline \hline Factors & Items \\
\hline GPEL & $\begin{array}{l}\text { I express my genuine contentment in relation to this hotel brand } \\
\text { I express my genuine concern about this hotel brand } \\
\text { I express my genuine happiness in relation to this hotel brand } \\
\text { I express my genuine liking towards this hotel brand } \\
\text { I express my genuine enthusiasm in relation to this hotel brand }\end{array}$ \\
$\begin{array}{l}\text { Faked positive emotional } \\
\text { labour }\end{array}$ & $\begin{array}{l}\text { Sometimes I fake my contentment in relation to this hotel brand } \\
\text { Sometimes I fake my concern in relation to this hotel brand } \\
\end{array}$ \\
& $\begin{array}{l}\text { Sometimes I fake my happiness in relation to this hotel brand } \\
\text { Sometimes I fake my liking towards this hotel brand } \\
\text { Sometimes I fake my enthusiasm in relation to this hotel brand }\end{array}$
\end{tabular}

Suppressed negative emotional labour

Sometimes I suppress my disliking towards this hotel brand Sometimes I suppress my aggravation in relation to this hotel brand Sometimes I suppress my anxiety in relation to this hotel brand Sometimes I suppress my sadness in relation to this hotel brand Sometimes I suppress my irritation towards this hotel brand Sometimes I suppress my fear of being abandoned by this hotel brand Sometimes I suppress my mental distress in relation to this hotel brand Sometimes I suppress my hatred towards this hotel brand Sometimes I suppress my anger towards this hotel brand

Hotel location emotion- Joy

Hotel location emotion- love

The location of this hotel makes me cheerful

The location of this hotel gives me pleasure

The location of this hotel gives me joy

I feel enthusiastic about the location of this hotel

The location of the hotel delights me

The location of this hotel evokes tenderness within me

The location of this hotel evokes love within me

I feel affectionate towards the location of this hotel

The location of this hotel is warm

I feel to take care of the environment of the hotel location

Hotel location emotion-positive surprise

The location of this hotel is amazing

The location of this hotel is astonishing

The location of this hotel is fascinating

The location of this hotel is inspiring

The location of this hotel is surprisingly beautiful

Social-self expressiveness of hotel brand

Getting associated with this hotel brand contributes to my social image Getting associated with this hotel brand adds to the social roles I play Being the customer of this hotel brand has a positive impact on what others think of me Getting associated with this hotel brand improves the way society views me

Emotional satisfaction

I don't feel happy at all with the service provided by this hotel/feel very happy with the service provided by this hotel

I don't at all feel pleasant while consuming the service of this hotel/feel very pleasant while consuming the service of this hotel

I don't at all feel joyful while consuming the service of this hotel/feel joyful while consuming the service of this hotel 
Table 1. Continue...

\begin{tabular}{|c|c|}
\hline Factors & Items \\
\hline \multicolumn{2}{|c|}{ Cognitive satisfaction } \\
\hline & I am satisfied with this hotel brand and the services provided by it \\
\hline & I would choose a different hotel brand in future* \\
\hline & My choice to come to this hotel has been a wise one \\
\hline & I feel good about my decision to come to this hotel \\
\hline & I am not happy with the service provided by this hotel brand* \\
\hline \multicolumn{2}{|c|}{ Brand loyalty } \\
\hline & This is the only hotel that I will come to in future whenever I will come to this place \\
\hline & $\begin{array}{l}\text { Whenever I will come to this destination, I will not even search for information about any hotel brand } \\
\text { other than this }\end{array}$ \\
\hline & $\begin{array}{l}\text { Anytime if this hotel is fully occupied and there is no vacancy, I will postpone my outing program to } \\
\text { this destination }\end{array}$ \\
\hline & I will cancel my outing program, rather than going to another hotel \\
\hline \multicolumn{2}{|c|}{$\begin{array}{l}\text { Hotel brand foreignness (de- } \\
\text { veloped country association) }\end{array}$} \\
\hline & $\begin{array}{l}\text { I don't think that consumers from developed foreign countries come to this hotel/I do think that con- } \\
\text { sumers from developed foreign countries come to this hotel }\end{array}$ \\
\hline & $\begin{array}{l}\text { To me, this hotel represents something associated with developed foreign country/To me, this hotel } \\
\text { represents something Indian* }\end{array}$ \\
\hline & I associate this hotel with things that are Indian/I do not associate this hotel with things that are Indian \\
\hline & $\begin{array}{l}\text { The appeal of this hotel is a very good symbol of developed foreign culture/The appeal of this hotel is } \\
\text { not a very good symbol of developed foreign culture* }\end{array}$ \\
\hline
\end{tabular}

Hotel service qualityemployees

The hotel employees are very

The hotel employees give prompt service

The hotel employees are always willing to help

The hotel employees are never too busy to respond to guests' requests

The hotel employees instil confidence in guests

The guests feel safe in the delivery of services by its employees

The hotel employees are very polite and courteous The hotel employees have the knowledge to answer questions from the guests

The hotel employees have adequate skills to perform the services

The hotel employees pay individual attention to the guests

The hotel employees deal with the guests in a caring fashion

The hotel employees keep the guests' best interests at their hearts

The hotel employees understand the specific needs of the guests 


\section{Statistical Tools Used}

Normality of each item of every scale was checked using Shapiro and Wilk (1965) test. As all the scales used were already validated in foreign country contexts, the reliability of each scale was checked in the Indian context by examining the CR values. Exploratory factor analysis was not done, as all the scales used already had been validated by prior research. However, inter-factor correlations were computed using SPSS 17. Next, the measurement model was examined by correlating all possible pairs of the latent factors, and running Confirmatory Factor Analysis (CFA) using LISREL 8.72. The CFA was followed by running Structural Equation Modelling (SEM) using LISREL 8.72 to test the hypothesized relationships. Covariance matrices were used and maximum likelihood approach was followed while doing both CFA and SEM. The sample size of 1052 was greater than 10 times the total number of scale items used in the questionnaire which according to A. Sarkar et al. (2012) is sufficiently large to run CFA and SEM.

\section{RESULTS}

For each item in every scale Shapiro-Wilk's $p$-value was insignificant $(p>0.05)$ showing that all scale items were normally distributed. All CR values were satisfactorily high $(>0.77$ ) which are shown in Table 1 establishing reliability of the scales in Indian context. The measurement model achieved a good fit (CMIN/DF = 2.649; CFI = 0.909; $\mathrm{NFI}=0.863$; RMSEA $=0.039$ ). All standardized dependent and correlated path coefficients in the measurement model were positive and significant at $5 \%$ level. Inter-factor correlations computed are reported in Table 2. An examination of the correlation values in Table 2 shows that FPEL and SNEL are correlated with the remaining factors weakly $(p<0.10)$. All other correlation values are significant at $5 \%$ level. The probable reason behind this is that emotional dissonance causing FPEL and SNEL were not felt significantly by our respondents, or the level of emotional dissonance felt by our respondents in relation to their loved hotel brands was low.

TABLE 2. Inter-factor correlation matrix

\begin{tabular}{|c|c|c|c|c|c|c|c|c|c|c|c|c|c|c|c|c|c|}
\hline & HBL & OCP-A & ОСР-B & CHS & OCP-S & CBL & GPEL & FPEL & HLE-J & HLE-L & PHBF & $\begin{array}{l}\text { HLE- } \\
\text { PS }\end{array}$ & HSQ-E & SSE & $\begin{array}{l}\text { HSQ- } \\
T\end{array}$ & AHS & SNEL \\
\hline \multicolumn{18}{|l|}{ HBL } \\
\hline OCР-A & 0.51 & & & & & & & & & & & & & & & & \\
\hline ОСР-В & 0.57 & 0.77 & & & & & & & & & & & & & & & \\
\hline CHS & 0.69 & 0.62 & 0.57 & & & & & & & & & & & & & & \\
\hline OCP-S & 0.53 & 0.75 & 0.73 & 0.66 & & & & & & & & & & & & & \\
\hline CBL & 0.78 & 0.53 & 0.49 & 0.53 & 0.55 & & & & & & & & & & & & \\
\hline GPEL & 0.76 & 0.61 & 0.53 & 0.69 & 0.61 & 0.66 & & & & & & & & & & & \\
\hline FPEL & $0.29 *$ & $0.25^{*}$ & $0.31^{*}$ & $0.34^{*}$ & $0.27^{*}$ & $0.32^{*}$ & $0.28^{*}$ & & & & & & & & & & \\
\hline HLE-J & 0.67 & 0.56 & 0.61 & 0.53 & 0.57 & 0.56 & 0.55 & 0.51 & & & & & & & & & \\
\hline HLE-L & 0.61 & 0.64 & 0.55 & 0.58 & 0.62 & 0.57 & 0.64 & 0.64 & 0.71 & & & & & & & & \\
\hline PHBF & 0.64 & 0.53 & 0.63 & 0.63 & 0.69 & 0.62 & 0.58 & 0.55 & 0.56 & 0.54 & & & & & & & \\
\hline HLE-PS & 0.57 & 0.65 & 0.57 & 0.56 & 0.54 & 0.69 & 0.67 & 0.62 & 0.73 & 0.75 & 0.61 & & & & & & \\
\hline HSQ-E & 0.56 & 0.68 & 0.71 & 0.65 & 0.68 & 0.74 & 0.63 & 0.71 & 0.55 & 0.62 & 0.79 & 0.67 & & & & & \\
\hline SSE & 0.68 & 0.67 & 0.59 & 0.68 & 0.65 & 0.53 & 0.59 & 0.52 & 0.64 & 0.52 & 0.55 & 0.68 & 0.72 & & & & \\
\hline HSQ-T & 0.78 & 0.69 & 0.62 & 0.77 & 0.59 & 0.65 & 0.73 & 0.66 & 0.78 & 0.69 & 0.77 & 0.82 & 0.75 & 0.68 & & & \\
\hline AHS & 0.66 & 0.62 & 0.67 & 0.59 & 0.78 & 0.71 & 0.77 & 0.64 & 0.81 & 0.74 & 0.72 & 0.77 & 0.65 & 0.72 & 0.69 & & \\
\hline SNEL & $0.28^{*}$ & $0.38^{*}$ & $0.37^{*}$ & $0.33^{*}$ & $0.42^{*}$ & $0.41^{*}$ & $0.31^{*}$ & $0.33^{*}$ & $0.38^{*}$ & $0.39 *$ & $0.32^{*}$ & $0.35^{*}$ & $0.28^{*}$ & $0.27^{*}$ & $0.31 *$ & $0.33^{*}$ & \\
\hline HSQ-R & 0.62 & 0.66 & 0.58 & 0.69 & 0.55 & 0.62 & 0.54 & 0.56 & 0.51 & 0.61 & 0.68 & 0.62 & 0.59 & 0.52 & 0.54 & 0.53 & 0.61 \\
\hline
\end{tabular}

Note: Only $\left({ }^{*}\right)$ marked correlation values were significant at $10 \%$ level, and all other values were significant at $5 \%$ level. The abbreviations for the construct names used are already given in the text.

Then, SEM was run to test all the hypothesized relationships. While doing the SEM analysis OCP, HSQ and HLE were modelled as constructs represented by several firstorder latent dimensions and not modelled as higher-order constructs, as conceptualized by the respective prior studies validating these scales. The model achieved a good fit. CMIN/DF, CFI, NFI and RMSEA values were respectively $2.161,0.926,0.871$ and 0.033 . Table 3 shows the standardized values of hypothesized paths, corresponding $t$-values and significance levels.

Table 3 shows that all hypothesized paths were significant at 5\% significance level except the paths between i) HBL and FPEL (H7a), and ii) HBL and SNEL (H7b). These two paths were weakly significant at $10 \%$ level only. This shows that brand love feelings of our respondents towards respective hotel brands were largely very deep, and they largely could not remember any significant occasion of suppressing negative and/or faking positive emotion in relation to their loved hotel brands. 
TABLE 3. SEM path coefficients

\begin{tabular}{llc}
\hline \hline Hypothesized Paths & $\boldsymbol{t}$-Values & Standardized Path Coefficients \& Significance Levels \\
\hline H1 & 3.427 & $0.68^{* *}$ \\
H1 & 4.183 & $0.71^{* * *}$ \\
H2 & 3.872 & $0.73^{* *}$ \\
H3 & 4.837 & $0.72^{* * *}$ \\
H4 & $0.75^{* *}$ \\
H5 & 3.625 & $0.81^{* *}$ \\
H6 & 4.639 & $0.75^{* * *}$ \\
H2 & 4.517 & $0.71^{* *}$ \\
H3 & 4.063 & $0.74^{* *}$ \\
H4 & 3.728 & $0.69^{* * *}$ \\
H5 & 3.903 & $0.82^{* *}$ \\
H1 & 4.737 & $0.81^{* *}$ \\
H2 & 4.821 & $0.78^{* * *}$ \\
H6 & 4.905 & $0.66^{* *}$ \\
H7 & 3.793 & $0.68^{* *}$ \\
H1 & 3.831 & $0.44^{*}$ \\
H2 & 2.715 & $0.38^{*}$ \\
\hline \hline
\end{tabular}

Note: $\left({ }^{* *}\right)=p<0.01 ;\left(^{* *}\right)=p<0.05 ;\left({ }^{*}\right)=p<0.10$ The abbreviations for the construct names used are given in the text.

\section{DISCUSSION}

The whole SEM model is statistically supported at a $5 \%$ significance level except H7b and H7c. Getting H7b and H7c weakly significant at a $10 \%$ level validates the notion that true brand lover would not feel strong emotional discrepancy while interacting with brand. The correlation matrix also supports this aspect, as FPEL and SNEL are weakly ( $p$ $>10 \%$ ) correlated with other constructs. The most important emerging market context specific finding is that perceived hotel brand foreignness positively impacts emerging market consumers' brand love through enhancing brand social-self expressiveness (Carroll \& Ahuvia, 2006) or social signalling brand value (Zhou et al., 2010). This aspect gets support from prior qualitative research on brand love conducted by A. Sarkar et al. (2012) in the context of Indian emerging market. Most importantly, the model validated shows that OCP, HSQ and SSE impact affective satisfaction through enhancing cognitive satisfaction, and affective satisfaction directly predicts brand love. Thus, the study confirms the stage-wise relationships between cognitive satisfaction, affective satisfaction and more affective brand love which gets theoretical support from (Oliver, 1999).

This study theoretically contributes to the domain of hotel brand love research by extending the works of Mattila (2006) and Ladhari (2009) which highlight the importance of enhancing tourists' emotional bonding towards hotel brands in creating hotel brand loyalty among young Asian tourists. Prior research developing and empirically validating any comprehensive theoretical model for hotel brand love amongst young Asian tourists is scarce. This research fills that knowledge gap. The study model vali- dated is highly comprehensive, as a wide variety of hotel service cues (OCP, HSQ and SSE) are included in the model. The theoretical model conceptualized and validated in this study is largely based on the notions that i) satisfaction predicts brand love (Carroll \& Ahuvia, 2006), and ii) cognitive (Brakus et al., 2009) and affective (Ladhari, 2009) satisfaction are psychometrically distinct from each other, and each of them are also distinct from brand love.

The final model validated in this study also contributes to the existing body of hotel service theory by showing that OCP (Brocato et al., 2012) and HSQ (N. Y. Wong \& Ahuvia, 1998) can together predict the variance in cognitive hotel brand satisfaction better, and cognitive hotel satisfaction is an antecedent of affective hotel satisfaction which is again supported by Oliver (1999). The model also shows that perceived foreignness of hotel brand enhances social self expressiveness of hotels in the eyes of young emerging market consumers which gets support from Zhou et al. (2010). This finding supports prior finding of J. G. Sarkar et al. (2015) that foreign acculturation is rapidly taking place among young Indian or Asian hotel consumers. The model examines the effect of young customer's hotel brand love on emotional labour for the first time in the domain of hospitality research, as prior research in this domain largely examined hotel employees' emotional labours in relation to interacting with employers, but not of the customers. Tourist's emotional labour is posited to be an important indicator of the intensity of hotel brand love, and this aspect has been largely ignored by prior research in the brand love domain subject to the fact that it is mostly difficult to ascertain the genuineness of consumer's emotional labour. 


\section{CONCLUSION}

This study shows that the tourists who would love a hotel brand might also fake positive emotion, and/or suppress negative emotion sometimes in order to maintain the love relationships with hotel till the hotel makes very major mistake. Thus, FPEL and SNEL might occur occasionally, and not very frequently in case of true love. This finding gets support from Hemetsberger et al. (2009) as already discussed. However, the question arises what type of mistake made by hotel would be considered as major that might lead to break down of brand love. There should be benchmarks for such major mistakes; so that any hotel service failure can be kept below the benchmark set. Future research should also be conducted to identify possible types of such major mistakes that can be committed by hotels.

\section{IMPLICATIONS}

\section{Implications for Future Research}

Future research directions would emerge from the limitations of the current study. Non-probability or convenient sampling is one limitation of this study. However, the sample size taken was significantly large which would have minimized the possible sampling error. The study considered only one construct relevant in emerging market context that is PHBF. More emerging market context specific variables should be considered by emerging market brand love researchers like the effects of Confucian values (N. Y. Wong \& Ahuvia, 1998). In order to make the questionnaire not very lengthy, Carroll and Ahuvia (2006) ten item uni-dimensional brand love scale was used. Future research should be conducted to test the model by taking Batra et al. (2012) multi-dimensional and more comprehensive brand love scale. It also cannot be claimed that the model is generalizable across Asian country markets or all emerging markets, as the model was tested only in one Asian country (India) context. Future research should test the model in multiple emerging market contexts.

\section{Managerial Implications}

The model validated in this study provides strategic guidelines to Indian hotel owners and managers in relation to the creation of a highly loved hotel brand among young consumers. According to the model, the hotel owners should first try to assess the probable emotional feelings of target tourists towards the place where they are planning to set up a hotel by conducting prior market surveys. The hotel located in emerging markets should have facilities at par with developed foreign country hotels subject to budget constraints, so that the emerging market tourists would perceive that association with the hotel brand would enhance their social-self images due to high PHBF. In order to enhance perceived hotel brand foreignness, an Indian hotel can try to make joint ventures with foreign hotels from developed countries, given that the Indian government has already liberalized foreign investment in Indian hotel sector. However, several Indian hotels i.e. Leela group of hotels are also entering into management contracts (in order to avoid the high cost of funds, and project delays generally involved in direct investments) which can also improve PHBF (Khan \& Sharma, 2013).

In addition to improving the HSQ dimensions (tangibles, service reliability, employees' behaviours), the hotel managers should develop certain policies to ensure that customers from appropriate target segments should largely come to the hotel. In this manner, customers simultaneously availing hotel services would generate positive OCP for each other. Brocato et al. (2012) rightly state, "Using the OCP scale along with traditional service quality measures (e.g., SERVQUAL), managers can gain deeper insight" into hotel customer relationship management. For example, a news channel in India has very recently reported an incident of not allowing a customer to enter the lounge by hotel staff for the stated reason of not being well dressed which went viral in social media (Banerjie, 2016). This shows that many hotels are trying to improve OCP in their service environments.

Before customers exit a hotel, managers can take qualitative and psychometric feedbacks of customers in order to uncover the true nature of emotional labours of target customers. For e.g., in the customer feedback form, there can be questions i.e., what is your overall impression of our service, or please suggest if there is any scope to improve the quality of service provided. This indirect and open-ended questions would help to uncover customers' GPEL and/or FPEL and/or SNEL. In the cases of FPEL and SNEL, proper reasons or gaps behind negative emotional dissonance need to be identified. Based on the identification of such gaps, the customers faking positive and/or suppressing negative emotions should be assured by hotel management that they don't need to do so, and specific service gaps responsible for such FPEL and/or SNEL would be filled up by following appropriate service gap filling strategy(Parasuraman, Zeithaml, \& Berry, 1985).

\section{REFERENCES}

Banerjie, M. (2016). Mocambo is racist: Facebook post on iconic Kolkata restaurant is viral. Retrieved from https://bit.1y/ 
2LBapRq (Accessed on 12 October, 2016)

Batra, R., Ahuvia, A., \& Bagozzi, R. P. (2012). Brand love. Journal of Marketing, 76(2), 1-16. doi:https://doi.org/10.1509/ jm.09.0339

Bergkvist, L., \& Bech-Larsen, T. (2010). Two studies of consequences and actionable antecedents of brand love. Journal of Brand Management, 17(7), 504-518. doi:https://doi.org/10.1057/bm.2010.6

Bitner, M. J. (1990). Evaluating service encounters: The effects of physical surroundings and employee responses. Journal of Marketing, 54(2), 69-82. doi:https://doi.org/10.2307/1251871

Blain, C., Levy, S. E., \& Ritchie, J. B. (2005). Destination branding: Insights and practices from destination management organizations. Journal of Travel Research, 43(4), 328-338. doi:https://doi.org/10.1177/0047287505274646

Brakus, J. J., Schmitt, B. H., \& Zarantonello, L. (2009). Brand experience: What is it? How is it measured? Does it affect loyalty? Journal of Marketing, 73(3), 52-68. doi:https://doi.org/10.1509/jmkg.73.3.52

Brocato, E. D., Voorhees, C. M., \& Baker, J. (2012). Understanding the influence of cues from other customers in the service experience: A scale development and validation. Journal of Retailing, 88(3), 384-398. doi:https://doi.org/10.1016/ j.jretai.2012.01.006

Bull, A. O. (1994). Pricing a motel's location. International Journal of Contemporary Hospitality Management, 6(6), 10-15. doi:https://doi.org/10.1108/09596119410070422

Carroll, B. A., \& Ahuvia, A. C. (2006). Some antecedents and outcomes of brand love. Marketing Letters, 17(2), 79-89. doi:https://doi.org/10.1007/s11002-006-4219-2

Catrett, J., \& Lynn, M. (1999). Managing status in the hotel industry: How four seasons came to the fore. Cornell Hotel and Restaurant Administration Quarterly, 40(1), 26-39. doi:https://doi.org/10.1177/001088049904000120

Chua, B. H., \& Iwabuchi, K. (2008). East asian pop culture: Analysing the Korean wave. Kowloon, Hong Kong: Hong Kong University Press.

Dwyer, L., Mellor, R., Livaic, Z., Edwards, D., \& Kim, C. (2004). Attributes of destination competitiveness: A factor analysis. Tourism Analysis, 9(1-2), 91-101. doi:https://doi.org/10.3727/1083542041437558

Glomb, T. M., \& Tews, M. J. (2004). Emotional labor: A conceptualization and scale development. Journal of Vocational Behavior, 64(1), 1-23.

Gretzel, U., Fesenmaier, D. R., Formica, S., \& O'Leary, J. T. (2006). Searching for the future: Challenges faced by destination marketing organizations. Journal of Travel Research, 45(2), 116-126. doi:https://doi.org/10.1177/0047287506291598

Grove, S. J., \& Fisk, R. P. (1997). The impact of other customers on service experiences: A critical incident examination of "getting along". Journal of Retailing, 73(1), 63-85. doi:https://doi.org/10.1016/s0022-4359(97)90015-4

Gu, H., Ryan, C., \& Yu, L. (2012). The changing structure of the Chinese hotel industry: 1980-2012. Tourism Management Perspectives, 4, 56-63. doi:https://doi.org/10.1016/j.tmp.2012.02.001

Helson, H. (1948). Adaptation-level as a basis for a quantitative theory of frames of reference. Psychological Review, 55(6), 297-313. doi:https://doi.org/10.1037/h0056721

Hemetsberger, A., Kittinger-Rosanelli, C. M., \& Friedmann, S. (2009). Bye bye love'-why devoted consumers break up with their brands. California, CA: ACR North American Advances.

Kandampully, J., \& Suhartanto, D. (2000). Customer loyalty in the hotel industry: The role of customer satisfaction and image. International Journal of Contemporary Hospitality Management, 12(6), 346-351.

Khan, S., \& Sharma, R. T. (2013). Hotel chains like leela, lemon tree, accor, IHG go for management deals over investment in properties. Retrieved from https://bit.ly/361UiPp (Access on 15 August, 2017)

Kim, H. J. (2008). Hotel service providers' emotional labor: The antecedents and effects on burnout. International Journal of Hospitality Management, 27(2), 151-161. doi:https://doi.org/10.1016/j.ijhm.2007.07.019

Kuo, M. P., \& Chen, Y. M. (2015). A study on the relationships among body sensory experience, customer satisfaction and customer loyalty-beauty SPA center as an example. International Journal of Business and Administrative Studies, 1(2), 61-67. doi:https://doi.org/10.20469/ijbas.10003-2

Kwortnik Jr, R. J., \& Ross Jr, W. T. (2007). The role of positive emotions in experiential decisions. International Journal of Research in Marketing, 24(4), 324-335. doi:https://doi.org/10.1016/j.ijresmar.2007.09.002

Ladhari, R. (2009). Service quality, emotional satisfaction, and behavioural intentions: A study in the hotel industry. Managing Service Quality: An International Journal, 19(3), 308-331. doi:https://doi.org/10.1108/09604520910955320 
Lam, W., \& Chen, Z. (2012). When I put on my service mask: Determinants and outcomes of emotional labor among hotel service providers according to affective event theory. International Journal of Hospitality Management, 31(1), 3-11. doi:https://doi.org/10.1016/j.ijhm.2011.04.009

Lee, J. J., \& Ok, C. (2012). Reducing burnout and enhancing job satisfaction: Critical role of hotel employees' emotional intelligence and emotional labor. International Journal of Hospitality Management, 31(4), 1101-1112. doi:https:// doi.org/10.1016/j.ijhm.2012.01.007

Lee, S. (2008). Internationalization of US multinational hotel companies: Expansion to Asia versus Europe. International Journal of Hospitality Management, 27(4), 657-664. doi:https://doi.org/10.1016/j.ijhm.2007.09.002

Lewis, R. C. (1985). Predicting hotel choice: The factors underlying perception. Cornell Hotel and Restaurant Administration Quarterly, 25(4), 82-96. doi:https://doi.org/10.1177/001088048502500415

Litteljohn, D. (1997). Internationalization in hotels: Current aspects and developments. International Journal of Contemporary Hospitality Management, 9(5/6), 187-192. doi:https://doi.org/10.1108/09596119710172534

Lockyer, T. (2005). Understanding the dynamics of the hotel accommodation purchase decision. International Journal of Contemporary Hospitality Management, 17(6), 481-492. doi:https://doi.org/10.1108/09596110510612121

Mann, S. (1999). Emotion at work: To what extent are we expressing, suppressing, or faking it? European Journal of Work and Organizational Psychology, 8(3), 347-369. doi:https://doi.org/10.1080/135943299398221

Martin, C. L. (1996). Consumer-to-consumer relationships: Satisfaction with other consumers' public behavior. Journal of Consumer Affairs, 30(1), 146-169. doi:https://doi.org/10.1111/j.1745-6606.1996.tb00729.x

Mason, D. D., Tideswell, C., \& Roberts, E. (2006). Guest perceptions of hotel loyalty. Journal of Hospitality \& Tourism Research, 30(2), 191-206. doi:https://doi.org/10.1177/1096348006286364

Mattila, A. S. (2006). How affective commitment boosts guest loyalty (and promotes frequent-guest programs). Cornell Hotel and Restaurant Administration Quarterly, 47(2), 174-181. doi:https://doi.org/10.1177/0010880405283943

Murphy, P., Pritchard, M. P., \& Smith, B. (2000). The destination product and its impact on traveller perceptions. Tourism Management, 21(1), 43-52. doi:https://doi.org/10.1016/s0261-5177(99)00080-1

Oliver, R. L. (1980). A cognitive model of the antecedents and consequences of satisfaction decisions. Journal of Marketing Research, 17(4), 460-469. doi:https://doi.org/10.1177/002224378001700405

Oliver, R. L. (1999). Whence consumer loyalty? Journal of Marketing, 63(4), 33-44. doi:https://doi.org/10.2307/1252099

Parasuraman, A., Zeithaml, V. A., \& Berry, L. L. (1985). A conceptual model of service quality and its implications for future research. Journal of Marketing, 49(4), 41-50. doi:https://doi.org/10.1177/002224298504900403

Pine, R. (2002). China's hotel industry: Serving a massive market. Cornell Hotel and Restaurant Administration Quarterly, 43(3), 61-70. doi:https://doi.org/10.1016/s0010-8804(02)80019-2

Qiu, H., Ye, B. H., Bai, B., \& Wang, W. H. (2015). Do the roles of switching barriers on customer loyalty vary for different types of hotels? International Journal of Hospitality Management, 46, 89-98. doi:https://doi.org/10.1016/j.ijhm.2015.01.015

Saputra, R., \& Dewi, C. K. (2016). The impact of brand trust on brand loyalty mediated by customer satisfaction: Case of Tokobagus.com (now OLX.co.id). Journal of Administrative and Business Studies, 1(1), 8-13. doi:https://doi.org/ $10.20474 /$ jabs-1.1.2

Sarkar, A., Ponnam, A., \& Murthy, B. K. (2012). Understanding and measuring romantic brand love. Journal of Customer Behaviour, 11(4), 324-347. doi:https://doi.org/10.1362/147539212x13546197909985

Sarkar, J. G., Sarkar, A., \& Ponnam, A. (2015). Exploration of brand sacralization among the young adult consumers in the context of emerging asian market. Young Consumers, 16(3), 264-280. doi:https://doi.org/10.1108/yc-12-2014 $-00499$

Shachar, R., Erdem, T., Cutright, K. M., \& Fitzsimons, G. J. (2011). Brands: The opiate of the nonreligious masses? Marketing Science, 30(1), 92-110. doi:https://doi.org/10.1287/mksc.1100.0591

Shapiro, S. S., \& Wilk, M. B. (1965). An analysis of variance test for normality (complete samples). Biometrika, 52(3/4), 591-611. doi:https://doi.org/10.1093/biomet/52.3-4.591

Shoval, N., McKercher, B., Ng, E., \& Birenboim, A. (2011). Hotel location and tourist activity in cities. Annals of Tourism Research, 38(4), 1594-1612. doi:https://doi.org/10.1016/j.annals.2011.02.007

Stiles, W. B., Putnam, S. M., Wolf, M. H., \& James, S. A. (1979). Interaction exchange structure and patient satisfaction with medical interviews. Medical Care, 17(6), 667-681. doi:https://doi.org/10.1097/00005650-197906000-00010 
Wong, K. K., \& Chi-Yung, L. (2002). Predicting hotel choice decisions and segmenting hotel consumers: A comparative assessment of a recent consumer based approach. Journal of Travel \& Tourism Marketing, 11(1), 17-33. doi:https:// doi.org/10.1300/j073v11n01_02

Wong, N. Y., \& Ahuvia, A. C. (1998). Personal taste and family face: Luxury consumption in confucian and western societies. Psychology \& Marketing, 15(5), 423-441. doi:https://doi.org/10.1002/(sici)1520-6793(199808)15:5<423:: aid-mar2>3.0.co;2-9

Xie, L., \& Chen, C.-C. (2014). Hotel loyalty programs: How valuable is valuable enough? International Journal of Contemporary Hospitality Management, 26(1), 107-129. doi:https://doi.org/10.1108/ijchm-08-2012-0145

Yaemjamuang, B. (2017). Investigating motivation of the hotel employees at the operational level: A case study of the hotel business in Samut Songkram Province, Thailand. International Journal of Business and Economic Affairs, 2(1), 8-11. doi:https://doi.org/10.24088/ijbea-2017-21002

Yang, Y., Wong, K. K., \& Wang, T. (2012). How do hotels choose their location? Evidence from hotels in Beijing. International Journal of Hospitality Management, 31(3), 675-685. doi:https://doi.org/10.1016/j.ijhm.2011.09.003

Yavas, U., \& Babakus, E. (2005). Dimensions of hotel choice criteria: Congruence between business and leisure travelers. International Journal of Hospitality Management, 24(3), 359-367. doi:ttps://doi.org/10.1016/j.ijhm.2004.09.003

Zhou, L., Yang, Z., \& Hui, M. K. (2010). Non-local or local brands? A multi-level investigation into confidence in brand origin identification and its strategic implications. Journal of the Academy of Marketing Science, 38(2), 202-218. doi:https:// doi.org/10.1007/s11747-009-0153-1 